\title{
The Adverse Effects of Androgen Deprivation Therapy in Prostate Cancer and the Benefits and Potential Anti-oncogenic Mechanisms of Progressive Resistance Training
}

Teresa Lam ${ }^{1,2,3^{*}}$ D, Vita Birzniece ${ }^{1,3,4,5,6}$, Mark McLean ${ }^{1,3}$, Howard Gurney ${ }^{7}$, Amy Hayden $^{7,8}$ and Birinder S. Cheema ${ }^{9}$

\begin{abstract}
Prostate cancer has the second highest incidence of all cancers amongst men worldwide. Androgen deprivation therapy (ADT) remains a common form of treatment. However, in reducing serum testosterone to castrate levels and rendering men hypogonadal, ADT contributes to a myriad of adverse effects which can affect prostate cancer prognosis. Physical activity is currently recommended as synergistic medicine in prostate cancer patients to alleviate the adverse effects of treatment. Progressive resistance training (PRT) is an anabolic exercise modality which may be of benefit in prostate cancer patients given its potency in maintaining and positively adapting skeletal muscle. However, currently, there is a scarcity of RCTs which have evaluated the use of isolated PRT in counteracting the adverse effects of prostate cancer treatment. Moreover, although physical activity in general has been found to reduce relapse rates and improve survival in prostate cancer, the precise anti-oncogenic effects of specific exercise modalities, including PRT, have not been fully established. Thus, the overall objective of this article is to provide a rationale for the in-depth investigation of PRT and its biological effects in men with prostate cancer on ADT. This will be achieved by (1) summarising the metabolic effects of ADT in patients with prostate cancer and its effect on prostate cancer progression and prognosis, (2) reviewing the existing evidence regarding the metabolic benefits of PRT in this cohort, (3) exploring the possible oncological pathways by which PRT can affect prostate cancer prognosis and progression and (4) outlining avenues for future research.
\end{abstract}

Keywords: Resistance training, Prostate cancer, Androgen deprivation therapy, Metabolic effects, Mitogenic pathways

\section{Key Points}

- Androgen deprivation therapy (ADT) is associated with adverse metabolic effects which can affect prognosis in men with prostate cancer.

- Progressive resistance training (PRT) is an exercise modality which can benefit both body composition and muscle function during ADT.

\footnotetext{
* Correspondence: Teresa.Lam@almedical.com.au

${ }^{1}$ School of Medicine, Western Sydney University, Penrith, NSW, Australia ${ }^{2}$ Department of Diabetes and Endocrinology, Westmead Hospital, Westmead, NSW, Australia

Full list of author information is available at the end of the article
}

- PRT may exert its positive effects on prostate cancer prognosis through its modification of cancer signalling pathways.

\section{Introduction}

Prostate cancer has the second highest incidence of all cancers amongst men worldwide and is the fifth leading cause of cancer death in men. In 2018, an estimated $1,276,106$ new cases of prostate cancer was reported worldwide, with higher prevalence in the developed countries [1]. The mechanisms of prostate carcinogenesis have marked heterogeneity and consist of both genetic and environmental factors, with risk of 
the disease increasing with age and positive family history [2]. Although androgens (including testosterone and dihydrotestosterone) affect proliferation and differentiation of prostate luminal epithelium and drive prostate cancer cell growth, there are conflicting data on the role of endogenous testosterone in human prostate cancer pathogenesis de novo. A pooled analysis of 18 prospective studies showed no association between the risk of prostate cancer and testosterone levels [3]. Yet, positive associations have been found between mutations in genes involved in the biosynthesis and degradation of testosterone, and higher prostate cancer risk $[4,5]$. Although similar controversies occur regarding the link between obesity, diabetes and risk of prostate cancer development [6-10], there is now strong evidence that being overweight or obese increases the risk of advanced prostate cancer [11].

Androgen receptor signalling strongly promotes growth, proliferation and invasiveness of prostate cancer. Thus, androgen deprivation therapy (ADT), using gonadotrophin-releasing hormone $(\mathrm{GnRH})$ analogues and/or anti-androgen agents, is a common and effective therapy for patients with locally advanced and metastatic prostate cancer. Long-acting $\mathrm{GnRH}$ analogues, such as leuprolide, cause downregulation of the pituitary-gonadal axis, resulting in 'chemical castration' due to suppression of testicular testosterone production. ADT leads to a decline of prostate-specific antigen (PSA) in about $90 \%$ of patients [12]. However, in rendering the patient severely hypogonadal, ADT is associated with significant adverse metabolic effects. Consequences of ADT include the development of insulin resistance, reduced muscle and bone mineral density (BMD), increased fat mass, sexual dysfunction and reduced quality of life $[13,14]$. Thus, there is a need for secondary treatment methods to combat the adverse effects of ADT.

Progressive resistance training (PRT) is an anabolic form of exercise that involves challenging the skeletal muscles with unaccustomed loads through use of free weights (e.g. barbells, dumbbells, medicine balls, sandbags), machine weights (e.g. leg press) and/or body weight (e.g. push-ups, pull-ups) and impact loading/ plyometric exercises such as jumping. To facilitate continued muscular anabolic adaptation over the long-term, training variables including intensity and volume must be manipulated over time [15]. It is well established that PRT can treat sarcopenia in older men and women (over 50 years) [16] and muscle wasting in some chronic diseases, including patients affected with end-stage renal disease [17] and AIDS-related muscle wasting [18]. The myogenic effect of PRT has been associated with many other beneficial physiological, functional and psychological adaptations across a range of healthy and chronically diseased populations. The benefits are likely to extend to patients with cancer. In fact, the Clinical
Oncology Society of Australia has recently endorsed the use of PRT as standard practice in cancer care [19].

To date, only a few robust studies have investigated the efficacy of PRT in patients receiving ADT for prostate cancer and the specific biological effects of this exercise modality are not completely understood in this cohort. Therefore, the overall objective of this review paper is to provide a rationale for the in-depth investigation of PRT and its biological effects in men with prostate cancer on ADT. This will be achieved by (1) summarising the adverse consequences of ADT in patients with prostate cancer and its effect on prostate cancer progression and prognosis, (2) summarising the existing evidence regarding the benefits of PRT in this cohort, (3) exploring the possible oncological pathways by which PRT can affect prostate cancer prognosis and progression and (4) outlining avenues for future research.

\section{Adverse Consequences of Androgen Deprivation Therapy and Their Potential Effects on Prostate Cancer Progression and Prognosis}

Androgens play a vital role in the regulation of body composition, insulin and glucose sensitivity, growth factors and inflammation. Thus, the development of hypogonadism following ADT is associated with multiple adverse effects which have potential negative effects on prostate cancer prognosis.

\section{Body Composition}

ADT is associated with a decrease in lean body mass (LBM) and increase in fat mass (FM), resulting in sarcopenic obesity [20]. These changes occur rapidly, starting after just 3 months of ADT [21, 22], with the average duration of therapy in high risk prostate cancer being 18 months [22]. After 1 year, FM has been shown to increase by $7-10 \%$, while LBM has been shown to decrease by $2-4 \%$ [23], ten times the annual loss occurring in aging [24]. These changes are sustained up to 2 years after initiating ADT [25]. Hamilton et al. found that ADT results in accumulation of both visceral (22\%) and subcutaneous (13\%) fat, with increased insulin resistance likely arising from visceral fat accumulation [26].

The consequences of sarcopenic obesity in men with prostate cancer are significant. Cheung et al. reported that long-term $\mathrm{ADT}$ was associated with a reduction in lower-limb muscle function. The muscle groups most affected are those involved in generating body-weight support and regulating gait and balance [27]. This leads to increased frailty, with a cross-sectional study showing that between 22 and $24 \%$ of current and past ADT users were recurrent fallers, compared to $5 \%$ of men not on ADT [28]. These falls were also more likely to result in injuries including haematomas and fractures [28]. 
Weight gain after a prostate cancer diagnosis is associated with poorer outcomes [29]. A higher baseline BMI correlates with greater prostate cancer specific mortality (PCSM) [30, 31] and obesity is associated with higher rates of biochemical recurrence after prostatectomy for early stage prostate cancer [32]. Furthermore, a metaanalysis of prospective cohort studies reported a $15 \%$ higher risk of PCSM per $5 \mathrm{~kg} / \mathrm{m}^{2}$ increase in BMI [33].

\section{Insulin Resistance and Diabetes Mellitus}

Insulin resistance and type 2 diabetes mellitus are known complications of ADT. Multiple prospective studies have shown decreased insulin sensitivity during ADT with a $25.9 \%$ increase in fasting plasma insulin levels and $12.8 \%$ reduction in insulin sensitivity after just 3 months [34]. After 1 year of ADT, insulin resistance as measured by HOMA-IR increased by $39 \%$ [35].

Multiple studies have also consistently reported a significant link between ADT and subsequent diagnosis of diabetes [36-38]. In a retrospective study of 12,191 men with prostate cancer, ADT was associated with a $60 \%$ increased risk of diabetes [39]. These changes in glucose metabolism occur before any changes in body composition are apparent, highlighting the direct effect of $\mathrm{ADT}$ on glucose metabolism.

Higher insulin and glucose levels are associated with a worse prostate cancer prognosis [40]. Higher c-peptide levels (surrogate marker for endogenous insulin production) are associated with increased risk of PCSM as well as high-risk prostate cancer (Gleason $\geq 7$ ) $[41,42]$. Similarly, a meta-analysis of 17 cohort studies showed that pre-existing diabetes was associated with a $29 \%$ increase in PCSM and 37\% increase in all-cause mortality in prostate cancer patients [43].

\section{Growth Factors and IGF-Binding Proteins}

There are many alterations in hormonal, metabolic and inflammatory pathways in response to ADT that may contribute to the development of diabetes and insulin resistance. Insulin-like growth factor-1 (IGF-1) is a peptide produced by the liver and is involved in regulation of cell proliferation and differentiation. IGF-1 exerts multiple effects on glucose, fat and protein metabolism. The production of IGF-1 is stimulated by growth hormone $(\mathrm{GH})$ secretion from the anterior pituitary gland which is potentiated by testosterone [44]. ADT has been shown to have either no effect on circulating IGF-1 or a $10 \%$ increase after 6 months of combined anti-androgen and GnRH therapy $[45,46]$. Higher serum levels of IGF1 are associated with increased all-cause mortality and PCSM in men with advanced prostate cancer [47]. These detrimental effects are also seen in studies of prostate cancer xenografts, where increased expression of IGF-1 and its receptor by prostate cancer cells results in tumour progression to castrate resistant prostate cancer (CRPC) [48].

The actions of the IGFs are modulated by a family of high-affinity IGF binding proteins (IGFBPs 1-6) which function to regulate IGF-1 and IGF-2 bioactivity [49]. IGFBP-2 is the main IGFBP produced by prostate epithelial cells, and is increased in patients with prostate cancer, correlating with tumour stage and grade [50]. Following androgen withdrawal, higher IGFBP-2 mRNA expression promotes androgen-independent tumour growth, and also correlates with a higher Gleason score $[51,52]$. Conversely, higher serum IGFBP-3 is associated with a lower risk of developing advanced-stage prostate cancer $[51,53]$ and studies show an increase in IGFBP-3 beginning within months of androgen withdrawal [54]. As IGFBP-3 is the principal binding protein for IGF-1, an increase in IGFBP-3 is expected to reduce IGF-1 bioavailability. Thus, higher circulating IGFBP-3 would be of great advantage in cancer patients, exerting direct effects on cancer cells as well as reducing IGF bioactivity.

\section{Lipid Profile}

ADT is associated with altered lipid metabolism. After 12 months of ADT, Smith et al. [55] found a 9.0\% increase in total cholesterol, $11.3 \%$ increase in high-density lipoprotein (HDL), 26.5\% increase in triglycerides and $7.3 \%$ increase in low-density lipoprotein (LDL). Like changes in body composition, these changes are rapid and can occur as early as 3 months following initiation of ADT [56].

Current evidence strongly suggests that lipid availability to cancer cells, whether newly synthesized or exogenously acquired, likely promotes prostate cancer growth and progression [57]. Elevated serum triglycerides are associated with increased risk of prostate cancer recurrence after a radical prostatectomy [58]. Similarly, high total cholesterol correlates with increased risk of lymph node metastases and high LDL levels are predictive of high Gleason scores [59]. Furthermore, elevated lipids, along with the aforementioned metabolic changes, also result in high cardiovascular mortality amongst prostate cancer patients receiving $\mathrm{ADT}[60]$.

\section{Cardiovascular Disease}

Cardiovascular disease (CVD) accounts for approximately a quarter of deaths amongst men with prostate cancer [61]. ADT may indirectly contribute to development of CVD by inducing metabolic changes that are well-established risk factors for development of atherosclerosis [62]. In addition, ADT interferes with the cardioprotective property of testosterone, increasing the risk of adverse events [63]. GnRH agonist-mediated immune activation has also been linked to CVD via fibrous cap disruption and plaque destabilisation by activated 
circulating $\mathrm{T}$ cells with the capacity to express the GnRH receptor [63]. There is clinical evidence which suggests a positive association between ADT and CVD [62]. A meta-analysis of six observational studies showed that the risk of cardiovascular mortality was $17 \%$ higher amongst those receiving ADT than those not receiving ADT [60]. O'Farrell et al. [63] found the highest risk of mortality in those with a history of CVD before cancer diagnosis, and in the first 6 months of ADT. For these reasons, the United States Food and Drug Administration has issued a warning on GnRH agonists for increased risk of diabetes and certain CVDs (heart attack, sudden cardiac death and stroke) [64].

\section{Changes in Other Hormonal Systems, Myokines Inflammatory Cytokines}

Circulating adipokines such as adiponectin and leptin are important regulators of insulin sensitivity. Prostate cancer patients undergoing ADT have leptin levels double that of those who have just undergone prostatectomy and/or radiotherapy without ADT [65]. Leptin levels increase in proportion to increase in fat mass, especially central adiposity. Studies of leptin levels and prostate cancer aggressiveness have produced mixed results. While some studies show a positive association between leptin levels and Gleason score [66, 67], others did not find serum leptin to be a predictive biomarker for advanced stage following radical prostatectomy [68].

Housa et al. [69] found higher adiponectin levels in locally advanced, compared to organ confined prostate cancer, and proposed that increased serum adiponectin levels may serve as a protective factor against tumour progression. Conversely, other studies found a negative association between plasma adiponectin levels and histological grade and stage [68, 70]. Levels of adiponectin have been found to increase with ADT [71, 72]. This is a paradoxical finding, as generally, adiponectin is characterised by a strong inverse correlation with fat mass and insulin resistance [71]. However, the increase in adiponectin does not seem sufficient to counteract the adverse effects of ADT on hyperinsulinaemia [73].

Pro-inflammatory cytokines have also been implicated in the development of diabetes and may be modulated by testosterone [74]. After 12 weeks of ADT, there is a fall in interleukin 6 (IL-6) levels along with higher levels of interleukin 1 beta (IL-1 $\beta$ ) and interleukin-8 (IL-8) [75]. Conversely, Maggio et al. found that 12 months of ADT did not affect plasma cytokine levels in men with prostate cancer [76]. Obesity is associated with a subclinical inflammatory state with higher plasma concentrations of pro-inflammatory mediators such as IL-6, tumour necrosis factor-alpha (TNF- $\alpha$ ) and IL-1 $\beta$ [77]. Based on epidemiological studies, higher IL-6 levels are associated with prostate cancer biochemical recurrence
[78] and poorer overall survival [79]. Increased serum IL-6 levels are also found in patients with castrateresistant and metastatic prostate cancer [79, 80]. Similarly, higher levels of TNF- $\alpha$ are associated with more aggressive disease, prostate cancer progression, relapse and mortality $[75,81,82]$.

\section{Effect on Bone Mineral Density}

$\mathrm{ADT}$ is associated with a significant reduction in bone mineral density (BMD), with more rapid bone loss compared to normal aging. Post-menopausal women experience an annual average of $3 \%$ decline in BMD at the spine [83]. Following initiation of ADT, the annual rates of bone loss at the lumbar spine and femoral neck regions have been reported as $4.6 \%$ and $3.8 \%$, respectively [84]. In a cross-sectional study, men with prostate cancer treated with ADT had a 7.2-7.8\% lower lumbar spine BMD, and trends towards a lower hip BMD compared to men not receiving ADT and healthy controls [85]. This reduction in BMD is translated into a higher fracture risk. In a large cohort study of 180,000 older men, ADT increased the relative risk of any fracture and hip fracture by 1.4 [86], thus increasing morbidity and mortality.

\section{Psychophysiological Effects}

The prevalence of depression and anxiety in men with prostate cancer across the treatment spectrum is high [87]. In particular, men receiving ADT have clinically significant decreased quality of life, particularly in the physical and sexual aspects compared to controls [88]. These psychological conditions are associated with psychophysiological side effects that encompass poorer treatment outcomes and reduced survival $[87,89,90]$. In turn, depression results in a chronically activated hypothalamo-pituitary-adrenal axis, immune dysfunction, inflammation, oxidative stress and increased cytokine production thus worsening cancer prognosis [91].

\section{Summary}

In summary, the negative systemic effects of ADT can potentially worsen prostate cancer prognosis. In the next section of this review, we discuss the clinical trials that utilise PRT in the treatment of these effects in prostate cancer.

\section{The Benefits of PRT During ADT PRT and Physiological Adaptations}

Muscle hypertrophy induced by PRT is the product of increased muscle fiber cross-sectional area [92] and is accompanied by the enhancement of subcellular structures (e.g. mitochondrial morphology and density) and increased substrate metabolism. This improvement in the metabolic capacity of skeletal muscle underlies a 
range of beneficial adaptations that may be particularly important to men treated with ADT.

Much of the current evidence regarding muscle adaptation in PRT is drawn from studies involving the elderly population with sarcopenia, a similar cohort to those on ADT [93]. In sarcopenia, there is a reduction in the number of both slow-twitch type I and fast-twitch type II muscle fibers and specific type 2 muscle fiber atrophy [94], leading to a decline in muscle strength [95]. PRT in this population has been shown to increase type IIa muscle fiber cross-sectional area [94, 96]. Thus, this physiological adaptation may improve physical function and contribute to improved glucose metabolism due to increased GLUT4 activity and enhanced insulin response via skeletal muscle [97]. Furthermore, PRT also has beneficial effects on mitochondrial function and proteostasis, the loss of which is implicated in the pathophysiology of muscle loss in sarcopenia [98].

\section{PRT in the Treatment of ADT-Induced Adverse Effects}

The benefits of isolated PRT in the treatment of ADTinduced adverse effects have been shown in five randomized controlled trials to date [99-103]. The details of each trial, including sample size, duration, type of intervention and findings, are summarized in Tables 1 and 2.

\section{Effect on Body Composition and Muscular Strength}

PRT has been shown to be beneficial in the maintenance of LBM during ADT. Alberga et al. [99] found that patients randomized to the PRT group was able to maintain total LBM as versus the control group. Similarly, Nilsen et al. [100] documented a site-specific increase in LBM of the lower limb, upper limb and appendicular region in patients receiving 16 weeks of PRT versus control. Skeletal muscle biopsies were collected in one trial [100]. Patients in the PRT group had a significant increase in total muscle fiber cross-sectional area, with the greatest effect noted in type II muscle fibers, as versus those in the control group, who had an overall reduction [104]. The number of myonuclei per type 1 fiber also increased in the PRT group.

There was a consistent improvement in both upper and lower arm strength across four trials following 3 to 12 months of PRT [99-102]. Taafe et al. [102] also reported an improvement in cardiorespiratory fitness in the PRT group, as reflected by an increase in the $400 \mathrm{~m}$ walk test.

PRT also has positive effects on FM. Alberga et al. [99] reported that percent body fat significantly increased in the control group versus the PRT group after 24 weeks. Likewise, Winters-Stone et al. reported a reduction in FM in patients undergoing PRT, as opposed to the control group who gained fat mass [103].

\section{Insulin Resistance and Type 2 Diabetes}

The effect of PRT in men on ADT has not been extensively evaluated. Only one trial by Winters-Stone et al. [103] reported a reduction in serum insulin and IGF-1 levels in the PRT group compared to an increase in both biomarkers in the control group.

\section{Bone Mineral Density}

Only two trials investigated bone mineral density (BMD) changes following 16 [100] and 52 [105] weeks of PRT. No differences in BMD outcomes were noted except preservation of BMD at the L4 site in patients in the PRT group versus the control group [105]. Bone turnover markers including osteocalcin and urinary deoxypyridinoline did not change [105].

\section{Psychological Effects}

Physical exercise is recognised as a powerful modulator of neuroplasticity and immune response with immunosurveillance-enhancing properties [106]. Healthrelated quality of life (HRQOL) was assessed in three studies [100-102]. Segal et al. [101] reported an improvement in HRQOL following PRT while no differences were found by Nilsen et al. [100]. Taafe et al. [102] found improvement in fatigue and vitality after 6 and 12 months of PRT.

\section{Summary}

In summary, PRT is beneficial in the treatment of ADTinduced adverse effects, with positive effects on body composition, muscle strength and cardiorespiratory fitness and QOL. However, there is currently inconclusive evidence establishing the relationship between PRT and prostate cancer progression and recurrence.

\section{The Effect of PRT on Cancer Growth Pathways}

In a prospective cohort study following over 2000 men with prostate cancer, it was found that men who were physically active lived significantly longer. Three or more hours per week of vigorous exercise was associated with a $61 \%$ decreased risk of dying from prostate cancer [107]. Although this association does not necessarily indicate causation, it has led to interest in exploring mechanisms by which exercise might favourably influence the biology of cancer cell growth. While it is known that exercise can lower the risk of developing cancer, and is associated with lower relapse rates and increased survival, its precise anti-cancer effects have not been fully established [89]. In the above, the important role of PRT in the treatment of the adverse effects of ADT was discussed. The next section provides a summary of current literature regarding the potential benefits PRT has on oncogenic pathways in prostate cancer. As there is currently a paucity of studies in this area, we also 


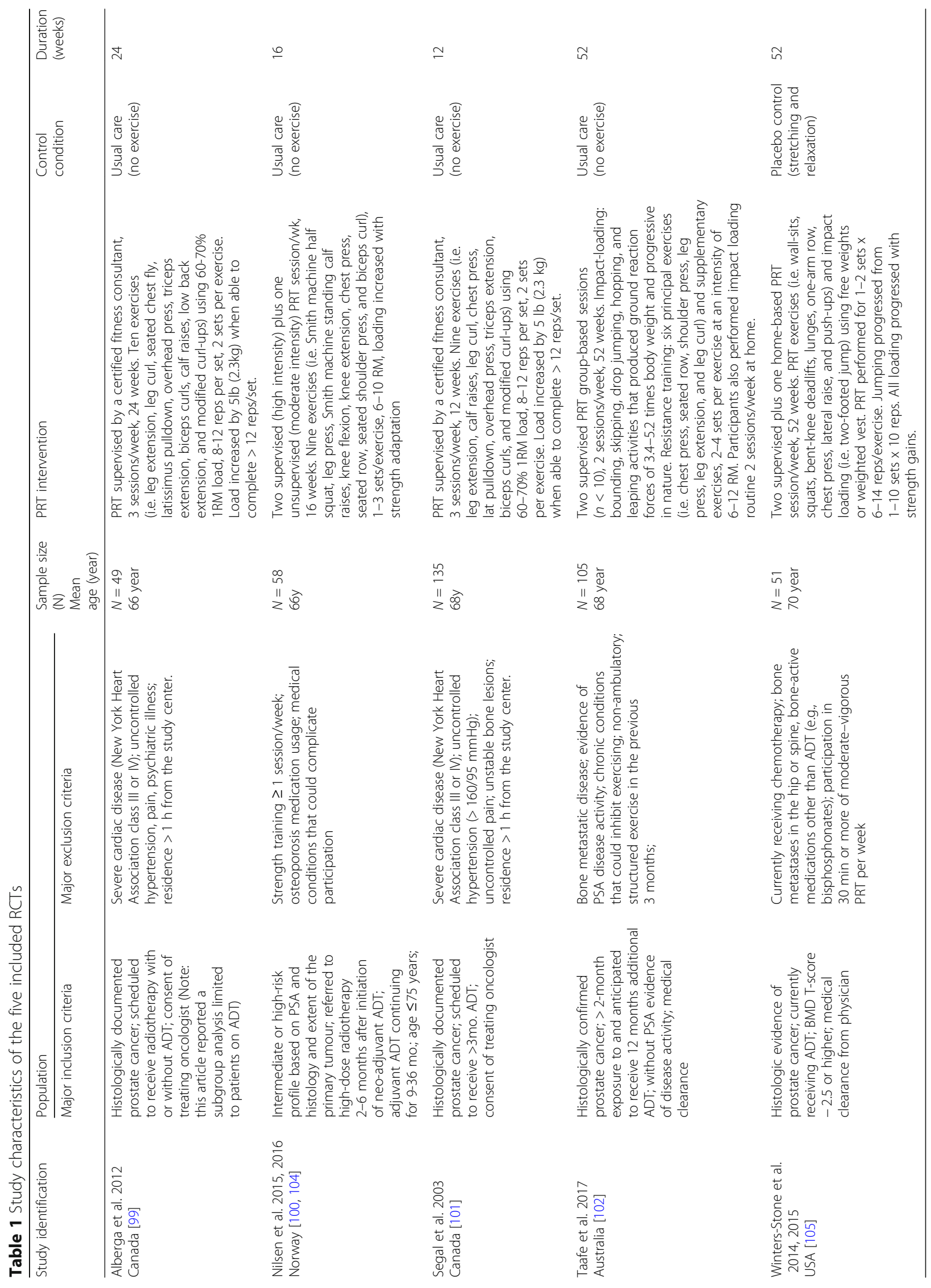




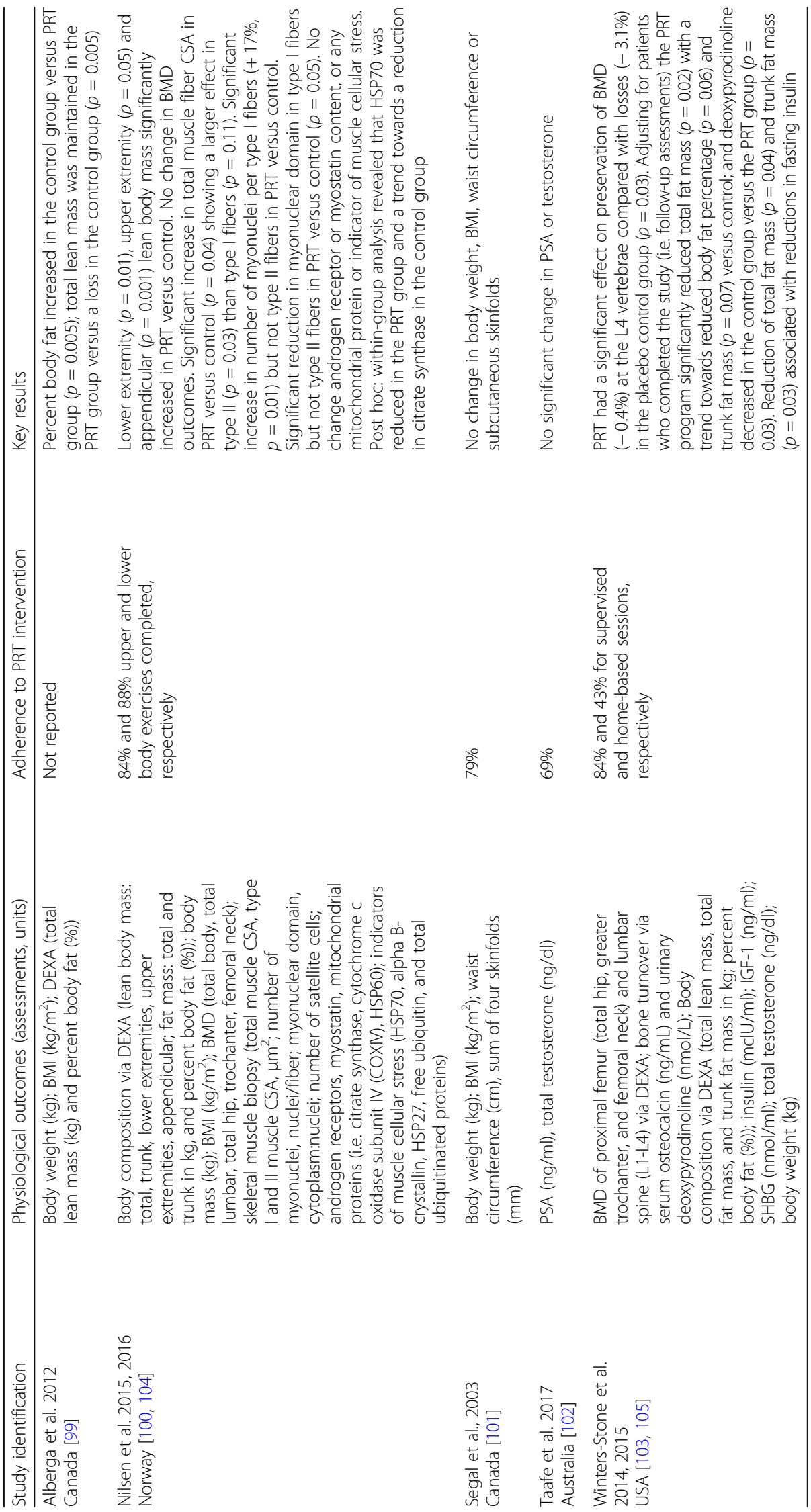


incorporate evidence derived from studies of other pathologies and cancer types. This is outlined in Fig. 1.

\section{Metabolic Effects}

Muscle tissue produces many factors that are associated with cancer progression and metastatic potential. When muscle contraction occurs during exercise, adenosine triphosphate (ATP) is consumed for energy derivation, reducing the adenosine monophosphate (ATP/AMP) ratio. This results in cellular activation of the liver kinase B1- (LKB1-) adenosine monophosphate-activated protein kinase (AMPK) pathway. AMPK inhibits the mammalian target of rapamycin (mTOR) protein, which has been implicated in prostate cancer progression [108]. Powerful muscle contraction results in potent stimulation of AMPK [109] which also results in translocation of the GLUT-4 membrane transporter in myocytes [110], leading to glucose influx and lowering of serum glucose levels, which has a favourable impact on prostate cancer prognosis [111]. Stimulation of AMPK also suppresses tumour growth, uptake of glucose and aerobic glycolysis of tumour cells, known as the Warburg effect [112].

Both insulin and IGF-1 regulate cell proliferation, differentiation, survival and apoptosis. These molecules bind to their tyrosine kinase receptors and activate several signalling pathways including phosphoinositide 3-kinase (PI3K)/protein kinase B (AKT)/mTOR resulting in inhibition of apoptosis and promotion of cell growth and angiogenesis [113]. The principal binding protein of IGF-1, IGFBP-3, can reduce IGF-1 bioactivity further inhibiting cancer growth [114]. IGFBPs not only modulate the bioavailability and signalling of IGFs but also have independent actions on cell growth and survival [49]. In-vitro studies have shown IGFBP-3 to inhibit proliferation, adhesion, invasion and metastasis of prostate cancer, independent of IGF-1 $[115,116]$. IGFBP-3 is also a potent inhibitor of MAPK signalling, which is implicated in the development of castrate-resistant prostate cancer [117]. Higher serum IGFBP-3 is associated with a lower risk of developing advanced-stage prostate cancer [53]. However, while PRT has been shown to reduce plasma IGF-1 [103] and increase IGFBP-3 [114] levels in prostate cancer, current epidemiological studies in cancer populations show significant heterogeneity in the response of the systemic IGF axis to exercise [118]. This discrepancy may be attributed to baseline concentrations of the IGF ligands, as Nishida et al. [119] showed that participants with elevated baseline IGF-1 experienced the greatest decrease in response to exercise. Furthermore, there are current limitations in oncological research regarding the exercise response of autocrine, as compared to systemic IGF-1 [118]. In older adults with rheumatoid arthritis, PRT increased total lean and appendicular muscle mass, which was associated with increases in muscular IGF-1 and IGFBP-3 with no changes in systemic levels [120]. Thus, more studies are required on the specific tissue response of the IGF-1 axis to PRT in prostate cancer.

\section{Chronic Inflammation and Antioxidant Pathways}

It is known that chronic inflammation in prostate cancer is associated with prostate cancer progression and poorer overall survival [81]. Stimulation of muscle contraction during PRT releases myokines that lower

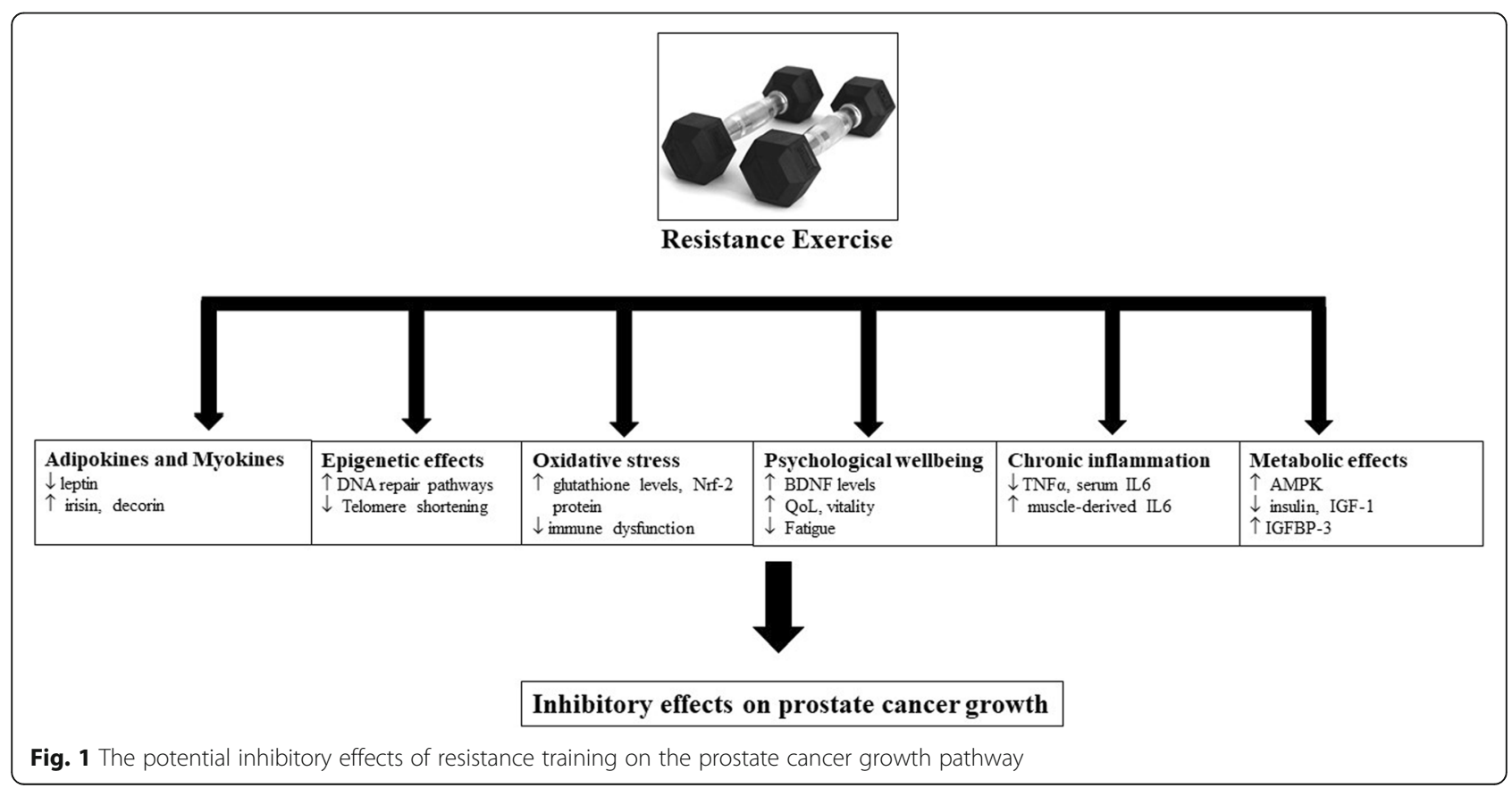


systemic inflammation [121], with 4-8 weeks of PRT reducing serum IL- 6 and TNF $\alpha$ in prostate cancer patients [122]. While IL-6 derived from macrophages and adipocytes has pro-inflammatory effects [121], muscle-derived IL-6 can counteract TNF- $\alpha$, which as previously discussed, is associated with significantly worse outcomes in men with prostate cancer [81]. Muscle-derived IL-6 acts as an energy sensor, and improves overall metabolic function by increasing insulin-stimulated glucose uptake and whole-body fatty acid oxidation [121]. Thus, modulation of systemic inflammation may represent one of the pathways in which PRT may inhibit prostate cancer progression.

Skeletal muscle is a major source of reactive oxygen species (ROS) which are balanced by antioxidant enzymes such as catalase, glutathione peroxidase and glutathione reductase [123]. ROS increase oxidative stress on DNA, which can contribute to the initiation and progression of prostate cancer [124]. In healthy young men, resistance exercise performed regularly for 6 weeks decreased oxidative stress and increased glutathione levels [125]. Prostate cancer patients who participated in vigorous activity had greater expression of the nuclear factor erythroid 2-related factor 2 (Nrf-2) in their normal prostate tissue compared to those who were more sedentary. The Nrf-2 protein stimulates the production of anti-oxidant enzymes, and studies in mice show that loss of Nrf-2 correlates with increased ROS and DNA damage leading to neoplastic transformation of normal prostate tissue [126].

\section{Adipokines and Myokines}

Leptin is an adipokine which is a key regulator of appetite control and body weight. It also has a role in energy homeostasis, insulin secretion, angiogenesis and modulation of innate and adaptive immune responses [127]. High circulating levels of leptin enhance growth of prostate cancer cells in vitro [128] and PRT has been found to significantly reduce serum leptin levels in obese men [129]. Resistin is an adipokine known to upregulate proinflammatory cytokines [130], and induce prostate cancer cell proliferation [131] while adiponectin has antiinflammatory properties [132]. PRT has been found to reduce serum resistin levels in post-menopausal women [133] while increasing serum adiponectin in obese young men [134], but has not been extensively studied in the cancer population.

Irisin is a myokine generated in the presence of exercise-induced upregulation of peroxisome proliferatoractivated receptor gamma coactivator-1-alpha (PGC-1 $\alpha$ ). It has a role in the regulation of energy metabolism, browning of white adipocytes and improving insulin sensitivity [135]. Irisin has been shown to significantly reduce cancer cell proliferation, migration and viability in malignant cancer cell lines without affecting nonmalignant cells. Specifically, irisin has cytotoxic effects on prostate cancer cells [136]. It has been suggested that endurance training can increase circulating irisin levels in human subjects [137]. Similarly, Zhao et al. [138] found that 12 weeks of PRT significantly increased serum irisin in older adults. Another potential pathway may involve decorin, which is a proteoglycan and a myokine, stimulated by resistance training [139]. Recent discoveries show that decorin reduces cancer growth and dissemination [140]. In prostate cancer cell models, decorin prevents androgen receptor nuclear translocation and inhibits the production of PSA [141]. In an animal model, systemic administration of decorin significantly reduced prostate cancer bone metastasis [142]. Thus, myokines released during muscle contraction may have a direct effect reducing cancer growth and spread.

\section{Neurotrophic Pathway}

Brain-derived neurotrophic factor (BDNF) is a member of the neurotrophin family of growth factors which supports differentiation, maturation and survival of neurons in the nervous system and a reduction in BDNF is implicated in the development of depression [143]. BDNF is also secreted by prostate cancer cells and has mitogenic effects on the prostatic epithelium [144]. A 12-week resistance training program in older male subjects was found to increase circulating plasma BDNF levels which returned to baseline after de-training [145]. Thus, the BDNF signalling pathway may represent one of the modalities by which resistance exercise inhibits prostate cancer cell growth.

\section{Epigenetic Effects}

Exercise has epigenetic effects on the phenotypic expression of various genes involved in cancer [89]. In men with low risk prostate cancer, cell cycling and DNA repair pathways were upregulated in those who participated in $\geq 3 \mathrm{~h} /$ week of vigorous activity compared to those who did not [146]. MicroRNAs (MiRNA) are small, endogenous non-coding RNA which can modify protein expression through cleavage of specific target mRNAs or through inhibition of their translation. In prostate cancer, the presence of oncogenic miRNAs such as miR-21 is predictive of cancer recurrence following radical prostatectomy [147], and serum levels of miR-21 have been found to decrease immediately after resistance exercise in healthy young men [148]. Dimauro et al. [149] found that 12 weeks of moderate intensity, explosive-type resistance training in an elderly cohort counteracts shortening of telomeres, which are nucleotides at the end of chromosomes that protect their integrity. Telomere shortening is one of the earliest molecular genomic events in prostate tumorigenesis and 
can generate genomic instability [150]. In men with early prostate cancer, those who followed a comprehensive lifestyle program, including regular exercise, had increases in telomere length after 5 years [151].

\section{Future Research Directions and Conclusion}

To conclude, as the population ages and the number of prostate cancer diagnoses increases across the population, we are likely to encounter more of the deleterious effects of ADT. There is now an endorsement by various oncological societies to incorporate the use of physical activity as synergistic medicine during prostate cancer treatment. PRT is an exercise modality that has been shown to be of benefit in the maintenance of body composition and muscle function during ADT, although it is important to note that current evidence exhibits major heterogeneity within and between studies in terms of patient characteristics and type of PRT intervention. Despite compelling evidence for the application of PRT as standard of care in patients with prostate cancer, there is still paucity in the literature regarding its use in this population. This includes its benefits on specific muscle groups, and its impact on physiological endpoints such as glucose and insulin metabolism, bone turnover and the adipokines, myokines and inflammatory cytokines affected during $\mathrm{ADT}$, thus providing scope for future research.

Furthermore, this review summarises the current body of evidence on the potential signalling pathways modified either directly or indirectly by PRT, and its positive effects on cancer growth and progression. As many of these pathways are also implicated in the development and progression of prostate cancer, more clinical studies are required in this area to obtain a better understanding of the mechanisms of benefit of PRT.

In summary, PRT is an exercise modality with great potential in the treatment of ADT-induced adverse effects. However, more research is required regarding its impact on the physiological and biochemical pathways involved in prostate cancer progression.

\section{Abbreviations}

ADT: Androgen deprivation therapy; AMP: Adenosine monophosphate; AMPK: Adenosine monophosphate-activated protein kinase; ATP: Adenosine triphosphate; BDNF: Brain-derived neurotrophic factor; BMD: Bone mineral density; CRPC: Castrate resistant prostate cancer; FM: Fat mass; GH: Growth hormone; GnRH: Gonadotrophin-releasing hormone; HbA1c: Glycosylated haemoglobin; HDL: High-density lipoprotein; HRQOL: Health-related quality of life; IGF-1: Insulin-like growth factor-1; IGFBP: IGF binding protein; IL1及: Interleukin 1 beta; IL-6: Interleukin 6; IL-8: Interleukin 8; LBM: Lean body mass; LDL: Low-density lipoprotein; MiRNA: MicroRNAs; mTOR: Mammalian target of rapamycin; Nrf-2: Nuclear factor erythroid 2-related factor 2; PCSM: Prostate cancer specific mortality; PGC-1a: Peroxisome proliferatoractivated receptor gamma coactivator-1-alpha; PI3K: Phosphoinositide 3kinase; PSA: Prostate-specific antigen; TNF-a: Tumour necrosis factor alpha
}

\section{Author's Contributions}

Teresa Lam is responsible for the preparation and writing of the manuscript. All authors have contributed to proof-reading of the manuscript and have approved the final article.

\section{Funding}

This research received no specific grant from any funding agency in the public, commercial or not-for-profit sectors.

Availability of Data and Materials

Not applicable.

Ethics Approval and Consent to Participate

Not applicable.

Consent for Publication

Not applicable.

\section{Competing Interests}

The authors, Teresa Lam, Vita Birzniece, Mark McLean, Howard Gurney, Amy Hayden, and Birinder S. Cheema, declare that they have no competing interests.

\section{Author details}

${ }^{1}$ School of Medicine, Western Sydney University, Penrith, NSW, Australia. ${ }^{2}$ Department of Diabetes and Endocrinology, Westmead Hospital, Westmead, NSW, Australia. ${ }^{3}$ Department of Diabetes and Endocrinology, Blacktown Hospital, Blacktown, NSW, Australia. ${ }^{4}$ School of Medicine, UNSW Sydney, Sydney, NSW, Australia. ${ }^{5}$ Garvan Institute of Medical Research, Darlinghurst, NSW, Australia. ${ }^{6}$ Translational Health Research Institute, Penrith, NSW, Australia. ${ }^{7}$ Crown Princess Mary Cancer Centre, Westmead, NSW, Australia. ${ }^{8}$ Department of Radiation Oncology, Blacktown Hospital, Blacktown, NSW, Australia. ${ }^{9}$ School of Science and Health, Western Sydney University, Penrith, NSW, Australia.

Received: 26 September 2019 Accepted: 5 February 2020

Published online: 13 February 2020

\section{References}

1. Bray F, Ferlay J, Soerjomataram I, Siegel RL, Torre LA, Jemal A. Global cancer statistics 2018: GLOBOCAN estimates of incidence and mortality worldwide for 36 cancers in 185 countries. CA Cancer J Clin. 2018:68:394-424.

2. Patel $A R$, Klein EA. Risk factors for prostate cancer. Nat Clin Pract Urol. 2009;6:87

3. Roddam AW, Allen NE, Appleby P, Key TJ. Endogenous sex hormones and prostate cancer: a collaborative analysis of 18 prospective studies. J Nat Cancer Inst. 2008;100:170-83.

4. Makridakis NM, Ross RK, Pike MC, Crocitto LE, Kolonel LN, Pearce CL, Henderson BE, Reichardt JK. Association of mis-sense substitution in SRD5A2 gene with prostate cancer in African-American and Hispanic men in Los Angeles, USA. Lancet. 1999;354:975-8.

5. Setiawan W, Schumacher FR, Haiman CA, et al. CYP17 genetic variation and risk of breast and prostate cancer from the National Cancer Institute Breast and Prostate Cancer Cohort Consortium (BPC3). Cancer Epidemiol Biomarkers Prev. 2007;16:2237-46.

6. Freedland SJ, Aronson WJ. Examining the relationship between obesity and prostate cancer. Reviews in urology. 2004:6:73-81.

7. Pelser C, Mondul AM, Hollenbeck AR, Park Y. Dietary fat, fatty acids, and risk of prostate cancer in the NIH-AARP diet and health study. Cancer Epidemiol Biomarkers Prev. 2013;22:697-707.

8. Kasper JS, Giovannucci E. A meta-analysis of diabetes mellitus and the risk of prostate cancer. Cancer Epidemiol Biomarkers Prev. 2006;15:2056-62.

9. Tseng C-H. Diabetes and Risk of Prostate Cancer. Diabetes Care. 2011;34:616.

10. Darbinian JA, Ferrara AM, Van Den Eeden SK, Quesenberry CP Jr, Fireman B, Habel LA. Glycemic status and risk of prostate cancer. Cancer Epidemiol Biomarkers Prev. 2008:17:628-35.

11. World Cancer Research Fund/American Institute for Cancer Research. Continuous Update Project Expert Report 2018. Diet, nutrition, physical activity and prostate cancer. Available at dietandcancerreport.org. 
12. Karantanos T, Corn PG, Thompson TC. Prostate cancer progression after androgen deprivation therapy: mechanisms of castrate resistance and novel therapeutic approaches. Oncogene. 2013;32:5501-11.

13. Galvao DA, Taaffe DR, Spry N, Joseph D, Newton RU. Cardiovascular and metabolic complications during androgen deprivation: exercise as a potential countermeasure. Prostate Cancer Prostatic Dis. 2009;12:233-40.

14. Chipperfield K, Fletcher J, Millar J, Brooker J, Smith R, Frydenberg M, Burney S. Predictors of depression, anxiety and quality of life in patients with prostate cancer receiving androgen deprivation therapy. Psychooncology. 2013.

15. Kraemer WJ, Ratamess NA, French DN. Resistance training for health and performance. Curr Sports Med Rep. 2002;1:165-71.

16. Peterson MD, Sen A, Gordon PM. Influence of Resistance Exercise on Lean Body Mass in Aging Adults: A Meta-Analysis. Med Sci Sports Exerc. 2011;43: 249-58.

17. Cheema B, Abas H, Smith B, et al. Progressive exercise for anabolism in kidney disease (PEAK): a randomized, controlled trial of resistance training during hemodialysis. J Am Soc Nephrol. 2007;18:1594-601.

18. Grinspoon S, Corcoran C, Parlman K, et al. Effects of testosterone and progressive resistance training in eugonadal men with AIDS wasting. A randomized, controlled trial. Ann Intern Med. 2000;133:348-55.

19. COSA Position Statement on Exercise in Cancer Care. Available at http:// www.cosa.org.au/media/332488/cosa-position-statement-v4-web-final.pdf.

20. Faris JE, Smith MR. Metabolic sequelae associated with androgen deprivation therapy for prostate cancer. Curr Opin Endocrinol Diabetes Obes. 2010;17:240-6.

21. Smith JC, Bennett S, Evans LM, Kynaston HG, Parmar M, Mason MD, Cockcroft JR, Scanlon MF, Davies JS. The effects of induced hypogonadism on arterial stiffness, body composition, and metabolic parameters in males with prostate cancer. J Clin Endocrinol Metab. 2001;86:4261-7.

22. Nabid A, Carrier N, Martin A-G, et al. Duration of androgen deprivation therapy in high-risk prostate cancer: a randomized phase III trial. Eur Urol. 2018;74:432-41.

23. Galvao DA, Nosaka K, Taaffe DR, Spry N, Kristjanson $\sqcup$, McGuigan MR, Suzuki K, Yamaya K, Newton RU. Resistance training and reduction of treatment side effects in prostate cancer patients. Med Sci Sports Exerc. 2006;38:2045-52.

24. Hughes VA, Frontera WR, Roubenoff R, Evans WJ, Singh MA. Longitudinal changes in body composition in older men and women: role of body weight change and physical activity. Am J Clin Nutr. 2002;76:473-81.

25. van Londen GJ, Levy ME, Perera S, Nelson JB, Greenspan SL. Body composition changes during androgen deprivation therapy for prostate cancer: a 2-year prospective study. Crit Rev Oncol Hematol. 2008;68: $172-7$.

26. Hamilton EJ, Gianatti E, Strauss BJ, Wentworth J, Lim-Joon D, Bolton D, Zajac $J \mathrm{D}$, Grossmann M. Increase in visceral and subcutaneous abdominal fat in men with prostate cancer treated with androgen deprivation therapy. Clin Endocrinol. 2011;74:377-83.

27. Cheung AS, Gray H, Schache AG, Hoermann R, Lim Joon D, Zajac JD, Pandy $M G$, Grossmann M. Androgen deprivation causes selective deficits in the biomechanical leg muscle function of men during walking: a prospective case-control study. J Cachexia Sarcopenia Muscle. 2017;8:102-12.

28. Winters-Stone KM, Moe E, Graff JN, Dieckmann NF, Stoyles S, Borsch C, Alumkal JJ, Amling CL, Beer TM. Falls and Frailty in Prostate Cancer Survivors: Current, Past, and Never Users of Androgen Deprivation Therapy. J Am Geriatr Soc. 2017;65:1414-9.

29. Strom SS, Wang X, Pettaway CA, Logothetis CJ, Yamamura Y, Do KA Babaian RJ, Troncoso P. Obesity, weight gain, and risk of biochemical failure among prostate cancer patients following prostatectomy. Clin Cancer Res. 2005;11:6889-94

30. Efstathiou JA, Bae K, Shipley WU, Hanks GE, Pilepich MV, Sandler HM, Smith MR. Obesity and mortality in men with locally advanced prostate cancer: Analysis of RTOG 85-31. Cancer. 2007;1 10:2691-9.

31. Smith MR, Bae K, Efstathiou JA, Hanks GE, Pilepich MV, Sandler HM, Shipley WU. Diabetes and mortality in men with locally advanced prostate cancer: RTOG 92-02. J Clin Oncol. 2008:26:4333-9.

32. Freedland SJ, Aronson WJ, Kane CJ, Presti JC Jr, Amling CL, Elashoff D, Terris MK. Impact of obesity on biochemical control after radical prostatectomy for clinically localized prostate cancer: a report by the Shared Equal Access Regional Cancer Hospital database study group. J Clin Oncol. 2004;22:446-53.

33. Cao Y, Ma J. Body mass index, prostate cancer-specific mortality, and biochemical recurrence: a systematic review and meta-analysis. Cancer Prev Res (Phila). 2011:4:486-501.
34. Smith MR, Lee $H$, Nathan DM. Insulin sensitivity during combined androgen blockade for prostate cancer. J Clin Endocrinol Metab. 2006;91:1305-8.

35. Harrington JM, Schwenke DC, Epstein DR, Bailey DE Jr. Androgendeprivation therapy and metabolic syndrome in men with prostate cancer. Oncol Nurs Forum. 2014;41:21-9.

36. Keating NL, O'Malley AJ, Smith MR. Diabetes and cardiovascular disease during androgen deprivation therapy for prostate cancer. J Clin Oncol. 2006;24:4448-56.

37. Lage MJ, Barber BL, Markus RA. Association between androgen-deprivation therapy and incidence of diabetes among males with prostate cancer. Urology. 2007;70:1104-8.

38. Alibhai SM, Duong-Hua M, Sutradhar R, Fleshner NE, Warde P, Cheung AM, Paszat LF. Impact of androgen deprivation therapy on cardiovascular disease and diabetes. J Clin Oncol. 2009;27:3452-8.

39. Tsai HT, Keating NL, Van Den Eeden SK, Haque R, Cassidy-Bushrow AE, Ulcickas Yood M, Smith MR, Potosky AL. Risk of diabetes among patients receiving primary androgen deprivation therapy for clinically localized prostate cancer. J Urol. 2015;193:1956-62.

40. Hammarsten J, Hogstedt B. Hyperinsulinaemia: a prospective risk factor for lethal clinical prostate cancer. Eur J Cancer. 2005;41:2887-95.

41. Ma J, Li H, Giovannucci E, Mucci L, Qiu W, Nguyen PL, Gaziano JM, Pollak M, Stampfer MJ. Prediagnostic body-mass index, plasma C-peptide concentration, and prostate cancer-specific mortality in men with prostate cancer: a long-term survival analysis. Lancet Oncol. 2008;9:1039-47.

42. Neuhouser ML, Till C, Kristal A, et al. Finasteride modifies the relation between serum C-peptide and prostate cancer risk: results from the Prostate Cancer Prevention Trial. Cancer Prev Res (Phila). 2010;3. https://doi.org/10.1158/1940-6207.CAPR-1 109-0188.

43. Lee J, Giovannucci E, Jeon JY. Diabetes and mortality in patients with prostate cancer: a meta-analysis. SpringerPlus. 2016;5:1548.

44. Birzniece V, Meinhardt UJ, Umpleby MA, Handelsman DJ, Ho KK. Interaction between testosterone and growth hormone on whole-body protein anabolism occurs in the liver. J Clin Endocrinol Metab. 2011;96:1060-7.

45. Hara N, Takizawa I, Isahaya E, Nishiyama T, Hoshii T, Ishizaki F, Takahashi K. Insulin-like growth factor-1 is associated with regulation of the luteinizing hormone production in men receiving androgen deprivation therapy with gonadotropin-releasing hormone analogues for localized prostate cancer. Urologic Oncol. 2012;30:596-601.

46. Dean JP, Sprenger CC, Wan J, et al. Response of the insulin-like growth factor (IGF) system to IGF-IR inhibition and androgen deprivation in a neoadjuvant prostate cancer trial: effects of obesity and androgen deprivation. J Clin Endocrinol Metab. 2013;98:E820-8.

47. Rowlands MA, Holly JM, Hamdy F, et al. Serum insulin-like growth factors and mortality in localised and advanced clinically detected prostate cancer. Cancer Causes Control. 2012;23:347-54.

48. Aggarwal RR, Ryan CJ, Chan JM. Insulin-like growth factor pathway: A link between androgen deprivation therapy (ADT), insulin resistance, and disease progression in patients with prostate cancer? Urol Oncol. 2013;31: 522-30.

49. Baxter RC. IGF binding proteins in cancer: mechanistic and clinical insights. Nat Rev Cancer. 2014;14:329-41.

50. Degraff DJ, Aguiar AA, Sikes RA. Disease evidence for IGFBP-2 as a key player in prostate cancer progression and development of osteosclerotic lesions. Am J Translat Res. 2009;1:115-30.

51. Figueroa JA, De Raad S, Tadlock L, Speights VO, Rinehart JJ. Differential expression of insulin-like growth factor binding proteins in high versus low Gleason score prostate cancer. J Urol. 1998;159:1379-83.

52. Kiyama S, Morrison K, Zellweger T, Akbari M, Cox M, Yu D, Miyake H, Gleave ME. Castration-induced increases in insulin-like growth factor-binding protein 2 promotes proliferation of androgen-independent human prostate LNCaP tumors. Cancer Res. 2003;63:3575-84.

53. Chan JM, Stampfer MJ, Ma J, Gann P, Gaziano JM, Pollak M, Giovannucci E. Insulin-like growth factor-I (IGF-I) and IGF binding protein-3 as predictors of advanced-stage prostate cancer. J Natl Cancer Inst. 2002;94:1099-106.

54. Kojima S, Mulholland DJ, Ettinger S, Fazli L, Nelson CC, Gleave ME. Differential regulation of IGFBP-3 by the androgen receptor in the lineagerelated androgen-dependent LNCaP and androgen-independent C4-2 prostate cancer models. Prostate. 2006;66:971-86.

55. Smith MR, Finkelstein JS, McGovern FJ, Zietman AL, Fallon MA, Schoenfeld DA, Kantoff PW. Changes in body composition during androgen deprivation therapy for prostate cancer. J Clin Endocrinol metabol. 2002;87:599-603. 
56. Smith MR, Lee $H$, McGovern F, Fallon MA, Goode M, Zietman AL, Finkelstein JS. Metabolic changes during gonadotropin-releasing hormone agonist therapy for prostate cancer: differences from the classic metabolic syndrome. Cancer. 2008;112:2188-94.

57. Stoykova GE, Schlaepfer IR. Lipid Metabolism and Endocrine Resistance in Prostate Cancer, and New Opportunities for Therapy. Int J Mol Sci. 2019;20.

58. Allott EH, Howard LE, Cooperberg MR, Kane CJ, Aronson WJ, Terris MK, Amling CL, Freedland SJ. Serum lipid profile and risk of prostate cancer recurrence: Results from the SEARCH database. Cancer Epidemiol Biomarkers Prev. 2014;23:2349-56.

59. Zhang G-M, Qin X-J, Zhang H-L, Xiao W-J, Zhu Y, Gu C-Y, Dai B, Shi G-H, Ye DW. Serum lipid profiles: novel biomarkers predicting advanced prostate cancer in patients receiving radical prostatectomy. Asian J Andrology. 2015;17:239-44.

60. Zhao J, Zhu S, Sun L, Meng F, Zhao L, Zhao Y, Tian H, Li P, Niu Y. Androgen deprivation therapy for prostate cancer is associated with cardiovascular morbidity and mortality: a meta-analysis of population-based observational studies. PloS One. 2014;9:e107516.

61. Lu-Yao G, Stukel TA, Yao SL. Changing patterns in competing causes of death in men with prostate cancer: a population based study. J Urol. 2004; 171:2285-90.

62. Zareba P, Duivenvoorden W, Leong DP, Pinthus JH. Androgen deprivation therapy and cardiovascular disease: what is the linking mechanism? Ther Adv Urol. 2016;8:118-29.

63. O'Farrell S, Garmo H, Holmberg L, Adolfsson J, Stattin P, Hemelrijck MV. Risk and Timing of cardiovascular disease after androgen-deprivation therapy in men with prostate cancer. J Clin Oncol. 2015;33:1243-51.

64. US Food and Drug Administration. FDA drug safety communication: update to ongoing safety review of $\mathrm{GnRH}$ agonists and notification to manufacturers of GNRH agonists to add new safety information to labelling regarding increased risk of diabetes and certain cardiovascular diseases. http://www.fda.gov/Drugs/DrugSafety/ucm229986.htm

65. Basaria S, Muller DC, Carducci MA, Egan J, Dobs AS. Hyperglycemia and insulin resistance in men with prostate carcinoma who receive androgendeprivation therapy. Cancer. 2006;106:581-8.

66. Chang S, Hursting SD, Contois $\mathrm{JH}$, et al. Leptin and prostate cancer. Prostate. 2001;46:62-7.

67. Saglam K, Aydur E, Yilmaz M, Goktas S. Leptin influences cellular differentiation and progression in prostate cancer. J Urol. 2003;169:1308-11.

68. Freedland SJ, Sokoll LJ, Mangold LA, Bruzek DJ, Mohr P, Yiu SK, Epstein Jl, Partin AW. Serum leptin and pathological findings at the time of radical prostatectomy. J Urol. 2005;173:773-6.

69. Housa D, Vernerova Z, Heracek J, Prochazka B, Cechak P, Kuncova J, Haluzik M. Adiponectin as a potential marker of prostate cancer progression: studies in organ-confined and locally advanced prostate cancer. Physiol Res. 2008; 57:451-8.

70. Burton A, Martin RM, Holly J, Lane JA, Donovan JL, Hamdy FC, Neal DE, Tilling K. Associations of adiponectin and leptin with stage and grade of PSA-detected prostate cancer: the ProtecT study. Cancer Causes Control. 2013:24:323-34

71. Rubinow KB, Snyder CN, Amory JK, Hoofnagle AN, Page ST. Acute testosterone deprivation reduces insulin sensitivity in men. Clin Endocrinol. 2012;76:281-8.

72. Urushima H, Inomata-Kurashiki $Y$, Nishimura $K$, Sumi R, Shimomura I, Nonomura N, Ito T, Maeda K. The effects of androgen deprivation therapy with weight management on serum aP2 and adiponectin levels in prostate cancer patients. Aging Male. 2015;18:72-6.

73. Kiwata JL, Dorff TB, Schroeder ET, Gross ME, Dieli-Conwright CM. A review of clinical effects associated with metabolic syndrome and exercise in prostate cancer patients. Prostate Cancer Prostatic Dis. 2016;19:323-32.

74. Norata GD, Tibolla G, Seccomandi PM, Poletti A, Catapano AL. Dihydrotestosterone decreases tumor necrosis factor-alpha and lipopolysaccharide-induced inflammatory response in human endothelial cells. J Clin Endocrinol Metab. 2006;91:546-54.

75. Saylor PJ, Kozak KR, Smith MR, Ancukiewicz MA, Efstathiou JA, Zietman AL, Jain RK, Duda DG. Changes in biomarkers of inflammation and angiogenesis during androgen deprivation therapy for prostate cancer. Oncologist. 2012; 17:212-9.

76. Maggio M, Blackford A, Taub D, Carducci M, Ble A, Metter EJ, Braga-Basaria M, Dobs A, Basaria S. Circulating inflammatory cytokine expression in men with prostate cancer undergoing androgen deprivation therapy. J Androl. 2006;27:725-8.
77. Kwon O-J, Zhang B, Zhang L, Xin L. High fat diet promotes prostatic basalto-luminal differentiation and accelerates initiation of prostate epithelial hyperplasia originated from basal cells. Stem Cell Res. 2016;16:682-91.

78. Alcover J, Filella X, Luque P, Molina R, Izquierdo L, Auge JM, Alcaraz A. Prognostic value of IL-6 in localized prostatic cancer. Anticancer Res. 2010; 30:4369-72.

79. George DJ, Halabi S, Shepard TF, Sanford B, Vogelzang NJ, Small EJ, Kantoff PW. The prognostic significance of plasma interleukin-6 levels in patients with metastatic hormone-refractory prostate cancer: results from cancer and leukemia group B 9480. Clin Cancer Res. 2005;11:1815-20.

80. Akimoto S, Okumura A, Fuse $H$. Relationship between serum levels of interleukin-6, tumor necrosis factor-alpha and bone turnover markers in prostate cancer patients. Endocrine J. 1998:45:183-9.

81. Michalaki V, Syrigos K, Charles P, Waxman J. Serum levels of IL-6 and TNFalpha correlate with clinicopathological features and patient survival in patients with prostate cancer. Br J Cancer. 2004;90:2312-6.

82. Nakashima J, Tachibana M, Ueno M, Miyajima A, Baba S, Murai M. Association between tumor necrosis factor in serum and cachexia in patients with prostate cancer. Clin Cancer Res. 1998;4:1743-8.

83. Kim DK, Lee JY, Kim KJ, Hong N, Kim JW, Hah YS, Koo KC, Kim JH, Cho KS. Effect of Androgen-Deprivation Therapy on Bone Mineral Density in Patients with Prostate Cancer: A Systematic Review and Meta-Analysis. J Clin Med. 2019;8:113.

84. Maillefert JF, Sibilia J, Michel F, Saussine C, Javier RM, Tavernier C. Bone mineral density in men treated with synthetic gonadotropin-releasing hormone agonists for prostatic carcinoma. J Urol. 1999;161:1219-22.

85. Dalla Via J, Daly RM, Owen PJ, Mundell NL, Rantalainen T, Fraser SF. Bone mineral density, structure, distribution and strength in men with prostate cancer treated with androgen deprivation therapy. Bone. 2019;127:367-75.

86. Wallander M, Axelsson KF, Lundh D, Lorentzon M. Patients with prostate cancer and androgen deprivation therapy have increased risk of fractures-a study from the fractures and fall injuries in the elderly cohort (FRAILCO). Osteoporos Int. 2019;30:115-25.

87. Watts S, Leydon G, Birch B, Prescott P, Lai L, Eardley S, Lewith G. Depression and anxiety in prostate cancer: a systematic review and meta-analysis of prevalence rates. BMJ Open. 2014;4:e003901.

88. Cheung AS, de Rooy C, Hoermann R, Lim Joon D, Zajac JD, Grossmann M. Quality of life decrements in men with prostate cancer undergoing androgen deprivation therapy. Clin Endocrinol. 2017;86:388-94.

89. Thomas RJ, Kenfield SA, Jimenez A. Exercise-induced biochemical changes and their potential influence on cancer: a scientific review. Brit J Sports Med. 2017:51:640.

90. Prasad SM, Eggener SE, Lipsitz SR, Irwin MR, Ganz PA, Hu JC. Effect of depression on diagnosis, treatment, and mortality of men with clinically localized prostate cancer. J Clin Oncol. 2014;32:2471-8.

91. Aldea M, Craciun L, Tomuleasa C, Crivii C. The role of depression and neuroimmune axis in the prognosis of cancer patients. J BUON. 2014;19:5-14.

92. Schoenfeld B. The use of specialized training techniques to maximize muscle hypertrophy. Strength Cond J. 2011;33:60-5.

93. Cheung AS, Zajac JD, Grossmann M. Muscle and bone effects of androgen deprivation therapy: current and emerging therapies. Endocr Relat Cancer. 2014;21:R371-94.

94. Verdijk LB, Gleeson BG, Jonkers RAM, Meijer K, Savelberg HHCM, Dendale P, van Loon LJC. Skeletal muscle hypertrophy following resistance training is accompanied by a fiber type-specific increase in satellite cell content in elderly men. J Gerontol A Biol Sci Med Sci. 2009;64:332-9.

95. Tieland M, Trouwborst I, Clark BC. Skeletal muscle performance and ageing. J Cachexia Sarcopenia Muscle. 2018;9:3-19.

96. Kosek DJ, Kim JS, Petrella JK, Cross JM, Bamman MM. Efficacy of 3 days/wk resistance training on myofiber hypertrophy and myogenic mechanisms in young vs. older adults. J Appl Physiol (1985). 2006;101:531-44.

97. Pesta DH, Goncalves RLS, Madiraju AK, Strasser B, Sparks LM. Resistance training to improve type 2 diabetes: working toward a prescription for the future. Nutr Metab (Lond). 2017;14:24.

98. Coen PM, Musci RV, Hinkley JM, Miller BF. Mitochondria as a target for mitigating sarcopenia. Front Physiol. 2019;9:1883.

99. Alberga AS, Segal RJ, Reid RD, Scott CG, Sigal RJ, Khandwala F, Jaffey J, Wells GA, Kenny GP. Age and androgen-deprivation therapy on exercise outcomes in men with prostate cancer. Support Care Cancer. 2012;20:971-81.

100. Nilsen TS, Raastad T, Skovlund E, Courneya KS, Langberg CW, Lilleby W, Fossa SD, Thorsen L. Effects of strength training on body composition, 
physical functioning, and quality of life in prostate cancer patients during androgen deprivation therapy. Acta Oncol. 2015;54:1805-13.

101. Segal RJ, Reid RD, Courneya KS, et al. Resistance exercise in men receiving androgen deprivation therapy for prostate cancer. J Clin Oncol. 2003;21: 1653-9.

102. Taaffe DR, Newton RU, Spry N, et al. Effects of different exercise modalities on fatigue in prostate cancer patients undergoing androgen deprivation therapy: a year-long randomised controlled trial. Eur Urol. 2017;72:293-9.

103. Winters-Stone KM, Dieckmann N, Maddalozzo GF, Bennett JA, Ryan CW, Beer TM. Resistance exercise reduces body fat and insulin during androgendeprivation therapy for prostate cancer. Oncol Nurs Forum. 2015;42:348-56.

104. Nilsen TS, Thorsen L, Fossa SD, Wiig M, Kirkegaard C, Skovlund E, Benestad $H B$, Raastad T. Effects of strength training on muscle cellular outcomes in prostate cancer patients on androgen deprivation therapy. Scand J Med Sci Sports. 2016;26:1026-35.

105. Winters-Stone KM, Dobek JC, Bennett JA, Maddalozzo GF, Ryan CW, Beer TM. Skeletal response to resistance and impact training in prostate cancer survivors. Med Sci Sports Exerc. 2014;46:1482-8.

106. Bortolato B, Hyphantis TN, Valpione S, et al. Depression in cancer: The many biobehavioral pathways driving tumor progression. Cancer Treat Rev. 2017; 52:58-70.

107. Kenfield SA, Stampfer MJ, Giovannucci E, Chan JM. Physical activity and survival after prostate cancer diagnosis in the health professionals follow-up study. J Clin Oncol. 2011;29:726-32.

108. Gao N, Zhang Z, Jiang BH, Shi X. Role of PI3KJAKT/mTOR signaling in the cell cycle progression of human prostate cancer. Biochem Biophys Res Commun. 2003;310:1124-32

109. Vavvas D, Apazidis A, Saha AK, Gamble J, Patel A, Kemp BE, Witters LA, Ruderman NB. Contraction-induced changes in acetyl-CoA carboxylase and 5'-AMP-activated kinase in skeletal muscle. J Biol Chem. 1997;272:13255-61.

110. Russell RR 3rd, Bergeron R, Shulman Gl, Young LH. Translocation of myocardial GLUT-4 and increased glucose uptake through activation of AMPK by AICAR. Am J Physiol. 1999;277:H643-9.

111. Wright JL, Plymate SR, Porter MP, Gore JL, Lin DW, Hu E, Zeliadt SB. Hyperglycemia and prostate cancer recurrence in men treated for localized prostate cancer. Prostate Cancer Prostatic Dis. 2013;16:204-8.

112. Faubert B, Boily G, Izreig $S$, et al. AMPK is a negative regulator of the Warburg effect and suppresses tumor growth in vivo. Cell Metabol. 2013;17: $113-24$.

113. Djiogue S, Kamdje AHN, Vecchio L, Kipanyula MJ, Farahna M, Aldebasi Y, Etet PFS. Insulin resistance and cancer: the role of insulin and IGFs. Endocr Relat Cancer. 2013;20:R1

114. Santa Mina D, Connor MK, Alibhai SM, Toren P, Guglietti C, Matthew AG, Trachtenberg J, Ritvo P. Exercise effects on adipokines and the IGF axis in men with prostate cancer treated with androgen deprivation: A randomized study. Can Urol Assoc J. 2013;7:E692-8.

115. Ingermann AR, Yang YF, Han J, et al. Identification of a novel cell death receptor mediating IGFBP-3-induced anti-tumor effects in breast and prostate cancer. J Biol Chem. 2010;285:30233-46.

116. Mehta HH, Gao Q, Galet C, et al. IGFBP-3 is a metastasis suppression gene in prostate cancer. Cancer Res. 2011;71:5154-63.

117. Mukherjee R, McGuinness DH, McCall P, Underwood MA, Seywright M, Orange C, Edwards J. Upregulation of MAPK pathway is associated with survival in castrate-resistant prostate cancer. Br J Cancer. 2011;104:1920-8.

118. Devin JL, Bolam KA, Jenkins DG, Skinner TL. The influence of exercise on the insulin-like growth factor axis in oncology: physiological basis, current, and future perspectives. cancer epidemiology, biomarkers \& prevention: a publication of the American Association for Cancer Research, cosponsored by the American Society of Preventive Oncology. 2016;25:239-49.

119. Nishida Y, Matsubara T, Tobina T, Shindo M, Tokuyama K, Tanaka K, Tanaka $H$. Effect of low-intensity aerobic exercise on insulin-like growth factor-I and insulin-like growth factor-binding proteins in healthy men. Int J Endocrinol. 2010;2010

120. Lemmey AB, Marcora SM, Chester K, Wilson S, Casanova F, Maddison PJ. Effects of high-intensity resistance training in patients with rheumatoid arthritis: a randomized controlled trial. Arthritis Rheum. 2009;61:1726-34.

121. Pedersen BK. Muscles and their myokines. J Exp Biol. 2011;214:337-46.

122. Fathollahi Shoorabeh F, Dabidiroshan V, Sheikh Saraf B, Nuri R. Investigating the effects of regular resistance training and prostatic massage on proinflammatory markers and serum prostate-specific antigen levels in males with prostate cancer. Middle East J Rehabil Health. 2016;3:e33651.
123. Accattato F, Greco M, Pullano SA, et al. Effects of acute physical exercise on oxidative stress and inflammatory status in young, sedentary obese subjects. Plos One. 2017;12:-e0178900.

124. Gupta-Elera G, Garrett AR, Robison RA, O'Neill KL. The role of oxidative stress in prostate cancer. Eur J Cancer Prev. 2012;21:155-62.

125. Cakir-Atabek H, Demir S, PinarbaSili RD, Gunduz N. Effects of different resistance training intensity on indices of oxidative stress. J Strength Cond Res. 2010;24:2491-7.

126. Frohlich DA, McCabe MT, Arnold RS, Day ML. The role of Nrf2 in increased reactive oxygen species and DNA damage in prostate tumorigenesis. Oncogene. 2008;27:4353-62

127. likuni N, Lam QLK, Lu L, Matarese G, La Cava A. Leptin and inflammation. Curr Immunol Rev. 2008:4:70-9.

128. Alshaker H, Sacco K, Alfraidi A, Muhammad A, Winkler M, Pchejetski D. Leptin signalling, obesity and prostate cancer: molecular and clinical perspective on the old dilemma. Oncotarget. 2015;6:35556-63.

129. Atashak S, Mohammad G, Faeze S. Effect of 10 week progressive resistance training on serum leptin and adiponectin concentration in obese men. British Journal of Sports Medicine. 2010;44:i29.

130. Jamaluddin MS, Weakley SM, Yao Q, Chen C. Resistin: functional roles and therapeutic considerations for cardiovascular disease. Br J Pharmacol. 2012; 165:622-32

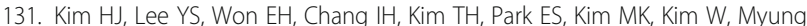
SC. Expression of resistin in the prostate and its stimulatory effect on prostate cancer cell proliferation. BJU Int. 2011;108:E77-83.

132. Ouchi N, Walsh K. Adiponectin as an anti-inflammatory factor. Clin Chim Acta. 2007;380:24-30.

133. Prestes J, Shiguemoto G, Botero JP, et al. Effects of resistance training on resistin, leptin, cytokines, and muscle force in elderly post-menopausal women. J Sports Sci. 2009:27:1607-15.

134. Moradi F. Changes of serum adiponectin and testosterone concentrations following twelve weeks resistance training in obese young men. Asian J Sports Med. 2015;6:-e23808.

135. Chen N, Li Q, Liu J, Jia S. Irisin, an exercise-induced myokine as a metabolic regulator: an updated narrative review. Diabetes Metab Res Rev. 2016:32:51-9.

136. Tekin S, Erden Y, Sandal S, Yilmaz B. Is Irisin an Anticarcinogenic Peptide? 4.

137. Qiu S, Cai X, Sun Z, Schumann U, Zugel M, Steinacker JM. Chronic exercise training and circulating irisin in adults: a meta-analysis. Sports Med. 2015;45: 1577-88.

138. Zhao J, Su Z, Qu C, Dong Y. Effects of 12 weeks resistance training on serum irisin in older male Adults. Front Physiol. 2017;8:171.

139. Kanzleiter T, Rath M, Gorgens SW, et al. The myokine decorin is regulated by contraction and involved in muscle hypertrophy. Biochem Biophys Res Commun. 2014;450:1089-94.

140. Neill T, Schaefer L, lozzo RV. Decorin as a multivalent therapeutic agent against cancer. Adv Drug Deliv Rev. 2016;97:174-85.

141. Hu Y, Sun H, Owens RT, Wu J, Chen YQ, Berquin IM, Perry D, O'Flaherty JT, Edwards IJ. Decorin suppresses prostate tumor growth through inhibition of epidermal growth factor and androgen receptor pathways. Neoplasia. 2009; 11:1042-53

142. Xu W, Neill T, Yang Y, et al. The systemic delivery of an oncolytic adenovirus expressing decorin inhibits bone metastasis in a mouse model of human prostate cancer. Gene Ther. 2015;22:247-56.

143. Bathina S, Das UN. Brain-derived neurotrophic factor and its clinical implications. Arch Med Sci. 2015;11:1164-78.

144. Montano X, Djamgoz MB. Epidermal growth factor, neurotrophins and the metastatic cascade in prostate cancer. FEBS Letters. 2004:571:1-8.

145. Nuvagah Forti L, Van Roie E, Njemini R, Coudyzer W, Beyer I, Delecluse C, Bautmans I. High versus low load resistance training: the effect of 24 weeks detraining on serum brain derived-neurotrophic factor (BDNF) in older adults. J Frailty Aging. 2017;6:53-8.

146. Magbanua MJ, Richman EL, Sosa EV, Jones LW, Simko J, Shinohara K, Haqq CM, Carroll PR, Chan JM. Physical activity and prostate gene expression in men with low-risk prostate cancer. Cancer Causes Control. 2014;25:515-23.

147. Li T, Li RS, Li YH, Zhong S, Chen YY, Zhang CM, Hu MM, Shen ZJ. miR-21 as an independent biochemical recurrence predictor and potential therapeutic target for prostate cancer. J Urol. 2012;187:1466-72.

148. Cui S, Sun B, Yin X, Guo X, Chao D, Zhang C, Zhang CY, Chen X, Ma J. Timecourse responses of circulating microRNAs to three resistance training protocols in healthy young men. Sci Rep. 2017;7:2203. 
149. Dimauro I, Scalabrin M, Fantini C, et al. Resistance training and redox homeostasis: correlation with age-associated genomic changes. Redox Biology. 2016;10:34-44

150. Graham MK, Meeker A. Telomeres and telomerase in prostate cancer development and therapy. Nat Rev Urol. 2017;14:607-19.

151. Ornish D, Lin J, Chan JM, Epel E, et al. Effect of comprehensive lifestyle changes on telomerase activity and telomere length in men with biopsyproven low-risk prostate cancer: 5-year follow-up of a descriptive pilot study. Lancet Oncol. 2013;14:1112-20.

\section{Publisher's Note}

Springer Nature remains neutral with regard to jurisdictional claims in published maps and institutional affiliations.

\section{Submit your manuscript to a SpringerOpen ${ }^{\circ}$ journal and benefit from:}

- Convenient online submission

- Rigorous peer review

- Open access: articles freely available online

High visibility within the field

- Retaining the copyright to your article

Submit your next manuscript at $\boldsymbol{\wedge}$ springeropen.com 